\section{sciendo}

Management Consulting Journal

Volume 5.1 | January 2022

DOI: $10.2478 / \mathrm{mcj}-2022-0007$

ISSN: $2631-987 X$

\title{
Consulting and the Pyramid of Trust
}

\author{
Martin Williams
}

\section{Introduction}

If I had a pound for every consulting firm that exclaimed to me, "We're the world's best kept secret!". It's as though it's a badge of honour. The fact is, most consulting firms are over-reliant on repeat business and referrals as their only sources of new leads. The problem, however, is that referrals are inconsistent, and repeat business is unlikely to be enough to truly scale the business. For such firms their growth strategy is simply a hope strategy. The likely outcome of this is a ticket to the revenue rollercoaster - where revenues are up one month, down the next. There's no predictability, there's a chaotic swing between feast and famine.

\section{The Pyramid of Trust}

A remedy is offered in the form the Pyramid of Trust. This is a three-stage framework to enable consulting firms to take a more proactive and considered approach to building a viable enterprise. The subject of trust is prominent in the consulting literature (Maister et al 2000, Schein 2016, Fields 2017) and trust building sits pretty much central to the activities of most effective consultants. Ingredients like clarity, proficiency, and consistency are trust-building qualities. In the marketing field, the value of taking a stepby-step approach and linking otherwise discrete activities together is widely understood and underpins many success marketing campaigns, for example, the AIDA (Attention, Interest, Desire, Action) pathway and the concept of the sales pipeline.

The Pyramid of Trust melds the concept of trust and trust building with business development process logic to create a framework specifically for the consulting context. Based on the three stages (Get Known, Build Trust, Generate Leads). Each of the three deals with target audiences in different states and suggests methods and approaches whose characteristics make them suitable for that stage of the process. The shape of the pyramid acknowledges that, at the start, the target audience is likely to be relatively broad. As the consultant moves up the pyramid (effort starts at the bottom and progresses upwards), the audience of interest narrows. Here's what it looks like: 


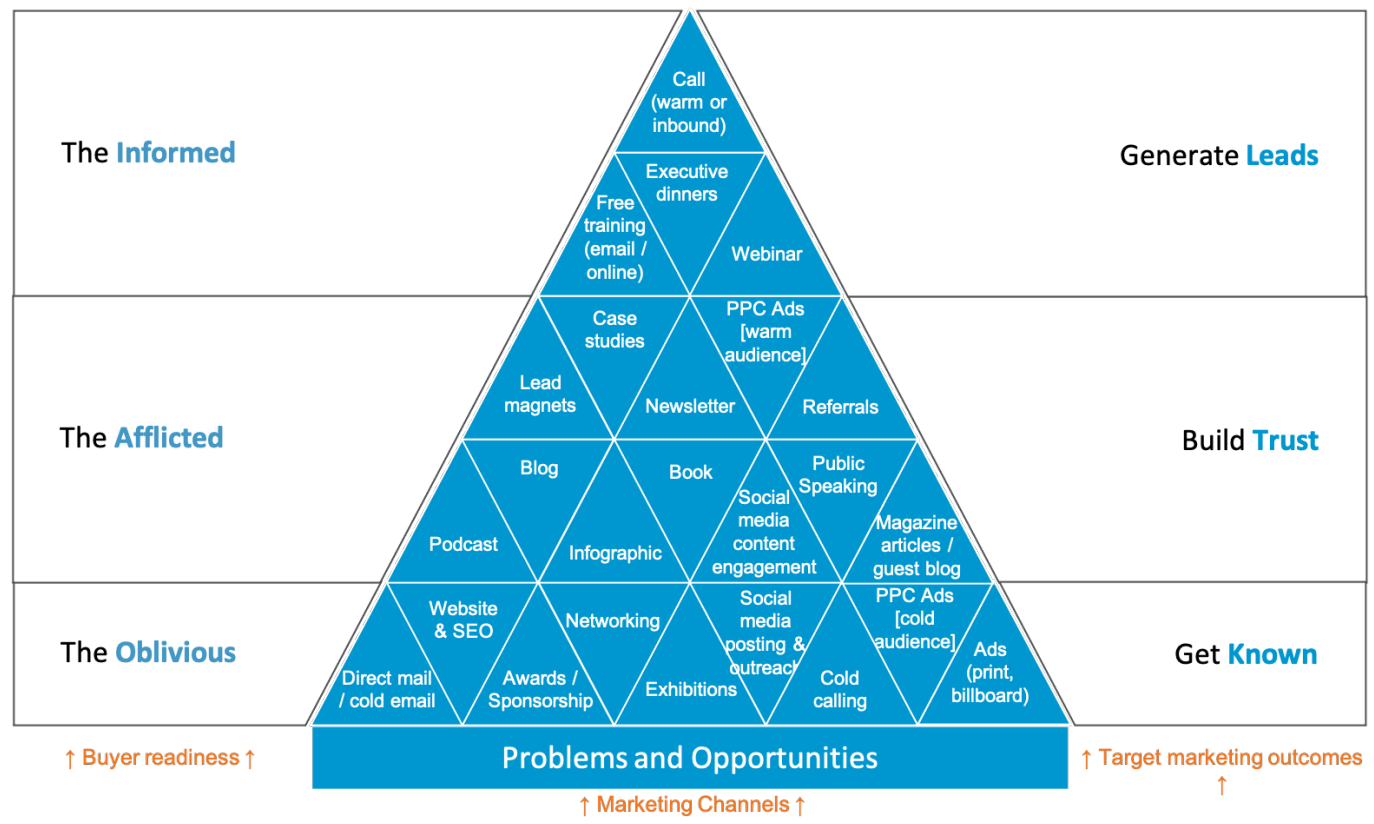

The first stage is to Get Known. It's important to recognise that your audience may not yet know of the challenges their organisations face and why consultants might be able to help. They're what we call Oblivious - they're nowhere near ready to buy, they may not know who you are, and they'll give you very little attention. To build this audience you'll need to choose marketing channels that have a broad appeal; for example, you might use Linkedin or networking. You are sensitising them to challenges they may face and ideally, your marketing content will enable you to get known for being the experts and having great capability in addressing these challenges.

The next stage in the pyramid is to Build Trust. Your audience has progressed to being Afflicted. That is, they're aware of the challenge that they face; they're looking for a solution. They're probably not ready to buy. They will, however, give you more time and attention. Since we know that your prospective clients want more information, and are prepared to invest more time, we should give them deeper content. For example, you might create an infographic to grab attention, go into more detail through a blog article, invite them to hear from you regularly by subscribing to your newsletter, and provide a free in-depth guide or template (aka lead magnets).

The top of the pyramid is the third stage, Generate Leads. Your audience has now become Informed. This means that they're aware of their problem or opportunity, they're actively seeking a solution, and through your consistent and focused efforts to date, your audience has come to know you and become more trusting of you. Your marketing will become more focused and intimate. You might put on an event, such as an inperson talk or a webinar, or perhaps an executive dinner, or even a free online course.

On reaching the pinnacle of the pyramid, you've shifted from a one-to-many conversation to a one-to-one. This is the point at which you handover a qualified lead to your sales process. 


\section{How to use the Pyramid of Trust}

Each consulting firm's Pyramid of Trust will be unique, as each reflects the context, target audience, expertise, and value propositions of the different consulting

enterprises. The Pyramid of Trust provides a basis for considering and designing an integrated business development approach that fits your own firm's circumstances. As the owner of a consulting firm and adviser to other consulting firms I can acknowledge the focus and logic the Pyramid of Trust offers. This, coupled with energy and discipline in its application, pays dividends. 


\section{References}

Fields, D.A. (2017) The Irresistible Consultant's Guide to Winning Clients, Morgan James Publishing

Maister, D.H., Green, C.H., Galford, R.N. (2000) The Trusted Advisor, Simon and Schuster

Schein, E.H., (2016) Humble Consulting, Berrett - Koehler 